\title{
Incidental Vocabulary Acquisition via Reading for Pleasure
}

\author{
FatemeMoradianFard ${ }^{* 1}$ and Samira Atefi Boroujeni ${ }^{1}$ \\ 1- MA in TEFL English teacher, Educational Office, Shahre Kord, Iran.
}

\begin{abstract}
This study intends to examine the incidental acquisition of vocabulary through reading for pleasure versus the intentional acquisition through the traditional method among the third grade students of high school in Iran, Shahre-Kord. The methodology: A group of 80 students were selected randomly from among the third grade students and a proficiency placement test already piloted with another similar group was given to them to build two homogenous groups and the extreme items were deleted. Students who scored between +-2SD were selected and divided into a control group and an experimental group. A pretest of vocabulary consisting of 48 unfamiliar vocabulary items extracted from eight short stories supposed to be used in the study was given to both groups. After analyzing, items known by $10 \%$ or so were excluded. The treatment: The experimental group was given eight short stories during 10-15 minutes of each class session. The new words occurred only once or twice in the short stories. The control group received no treatment, just were asked to read the 40 new vocabulary items in a list, accompanied with their L1 (Persian) equivalents. Then, a post-test consisting of the same 40 items was given to both groups. Statistical t-test showed no significant difference between the mean scores of the proficiency tests and the pre-tests in both groups. But, the t-test between the mean scores of posttests yielded a significant difference at 0.5 level of significance between two groups, i.e., the amount of acquisition of vocabulary in the experimental group was higher than that of the control group.
\end{abstract}

Key words: Incidental acquisition- intentional acquisition-vocabulary-reading for pleasure-

\section{Introduction}

A prerequisite for learning a second or a foreign language is that the learner is exposed to the language, in writing and /or in speech. Such language exposure or input my either be comprehensible or incomprehensible to the learner [2]. Since vocabulary is a sizable component in the learning process, learners across proficiency levels will encounter situations where they can understand only part of the written text or a sentence due to the fact that they do not know all the words. Encountering some unknown words might not hinder the overall understanding of the text, but if too many words or the most essential ones are unknown, then comprehension will suffer [3].Though too many techniques and procedures have been suggested for teaching vocabulary, incidental learning seems to be one of the most fruitful, which is in contrast to intentional learning [14]. Fodor (1983 [5]) offers these definitions for incidental learning: "a natural and individual response to the learning experience as a whole, learning not intended to as part of a course; learning that included skill, attitudes, and information which the participants did not intend to acquire from the course, but nevertheless did learn. The present study also intended to investigate if incidental learning of words from context would take place as a result of minimum exposure through reading for pleasure and if it was applicable to incorporate a reading for pleasure activity in the curriculum of high schools in Iran. Since this study aimed at measuring and comparing the amount of incidental vocabulary learning among the Iranian students studying English as a FL, the participants were selected from among the third grade students of a high school in Shahre-Kord city. The participants consisted of a control group and an experimental group.

\section{I.1. Literature Review}

Vocabulary has been a neglected area for a long time [18], even though it is essential for the mastery of language. Rivers (1988 [16]) has also argued that the acquisition of adequate vocabulary is essential for successful second language use because without an extensive vocabulary, we will not be able to use the structures and functions we may have learned for comprehensible communication. Hulstijn (2004 [7]) and Read (1988 [13]) also point out that many second language learners are severely hampered in reading comprehension and other skills by a simple lack of word knowledge. To overcome this problem, language practitioners have been using direct instruction to teach vocabulary.

However, studies by Jenkins \& Dixon (1983 [8]) and Rieder (2006 [15]) revealed that only a small percentage of words is learned via direct instruction. In fact, some studies have shown that vocabulary growth in a second language occurs through leisure reading $[12,9]$.Therefore, further research on using reading to enhance students' vocabulary should be carried out.

In Krashen's (1989 [9] ) opinion, results of studies in both first and second language acquisition support the view that comprehensible input, that is, input that is meaningful to and understood by the reader is 
the major source of vocabulary and spelling competence. According to the Input Hypothesis theory (IH), second /foreign language is subconsciously acquired by focusing on the message and not on the form [9]. Thus, the acquisition process is identical to what has been termed as "incidental learning" [9].

Honeyfield (1977 [18]) stresses on the importance of context in the teaching of vocabulary. He also points out that learners should be provided with strategies for inferring the meaning of unknown vocabulary from the context in which it occurs. In fact, several studies [11, 6]. Have shown that learning of word meanings from written context is potentially viable method even though the word knowledge grows in small increments. Thorny (2003) also introduces short literary texts as a type of genre and believes that they offer multiple possibilities for vocabulary development. Specially, he mentions short stories and argues that they are an exceptionally good way to promote second language acquisition especially through giving learners opportunities for pleasure reading.

\section{I.2.the Aim of the Study}

In the present situation of EFL in Iran, it seems that the ultimate goal of learning English at high schools is to develop the students' reading skills and to prepare them to be able to read English literature and more importantly scientific texts. However, most students at this level, find it difficult to comprehend texts, converse or write well in the English language possibly due to their low level of English vocabulary knowledge. However, little has been done to overcome this problem, as language teachers are constantly under pressure to teach all language skills simultaneously. In addition, some students themselves are not interested in reading books and articles written in English as they have problems understanding these texts. Findings by Greaney and Hegarty (1987 [6]) suggest that in developing the leisure time reading habit and at the same time, developing students' vocabulary knowledge, their attitude towards reading is an important factor in its own right. Therefore, it is vital to incorporate a reading for pleasure activity in the language curriculum so as to increase the reading habit in students. Jenkins et al (1984 [9]) as well as Stahl \& Fair Banks (1986 [17]) also revealed that students perform better when unfamiliar words are repeated more frequently through reading for pleasure. Allen (1983 [1]) also argues that: "Learning vocabulary requires more than a dictionary. Vocabulary is a cultural phenomenon as well as a linguistic one. ....Students must learn the social meaning of words in a foreign language in their right context (italics added), not just the equivalent word in their native tongue.

Regarding all the above findings, the aim of this study was also to develop the habit of pleasure reading in the students and to see whether incidental vocabulary learning from context would take place as a result of minimum exposure through reading for pleasure and to compare the amount of the acquisition of vocabulary incidentally in text to its acquisition intentionally, out of context, or in isolation.

\section{I.3. the Null Hypotheses of the Research}

The null hypotheses considered in this study were as follows:

1. Incidental acquisition of words does not occur as a result of minimum exposure to language through reading for pleasure?

2. There is no difference between the amounts of vocabulary acquisition incidentally in the experimental group with the amount of vocabulary learning intentionally in the control group.

\section{Materials and Methods}

\section{II.1. Methodology}

The participants in this study were selected through random sampling and consisted of two groups. A control group and an experimental group, both of which were selected from among the third grade students of high school in Shahre-Kord - Iran studying English as a FL and holding an intermediate level of knowledge in English. The whole participants consisted of 80 students.

\section{II.2. Materials}

The following materials were used in this study.

1- Nelson Proficiency test, 2- Teacher-made proficiency test, 3- Vocabulary pre-test, 4- Eight short stories, and 5- Vocabulary post-test.

\section{II.3. Procedures}

This study applied an experimental design consisting of pre-test, treatment, and post-test. However, through different phases of study, the following procedures were applied. Firstly, Nelson tests were considered to be applied as placement test to build two homogeneous groups to participate in the study. In order to investigate the appropriateness of the Nelson tests for the knowledge level of participants, a pilot study seemed to be necessary. Thus, a section of Nelson tests (Fowler and Coe, 1976, p. 40) prepared for intermediate level of knowledge in English was selected and given to a third group of students with the same level of knowledge to 
apply as a pilot study. However, the proficiency test yielded to be invalid, and impractical for the purpose of this study, since these tests have not been developed based on the English knowledge level and the textbook materials of Iranian students. Thus, the researcher developed a proficiency test considering the structural points and vocabulary items covered in students' textbooks so far and gave it to a third group of students, similar in knowledge level to the participants of study. After the item analysis of the test, a new test was developed and was given to the participants as a placement test. Those students whose scores fell between 1 SD below and above the mean were selected to participate in this study. They were divided into two groups, 30 in the experimental group and 30 in the control group. Then, the reliability of the teacher-made test was calculated. In the next phase of the study, a list of 48 vocabulary items found in the short stories, which were probable to be unfamiliar for the participants considering the vocabulary items of students' textbooks were selected and given to the participants of both groups as a pre-test and were asked to write their L1 meanings. After the process of item analysis, 8 vocabulary items which were known by $80 \%$ or more of the participants were omitted and the rest 40 items were considered to in the treatment part of the study. In this part, the experimental group read eight short stories, each at first 10-15 minutes of the class time. Students were asked to guess the meaning of new words. The control group, on the contrary was supposed to learn the meaning of unknown words through the traditional method of learning that is in isolation or in a list accompanied with their L1 equivalents. The participants of both groups were not preannounced for a post-test. Finally, a post-test was given to both groups containing the same 40 vocabulary items and they were asked to write their Persian meaning to compare the amount of acquisition in both groups.

\section{Result}

The results of descriptive statistics of proficiency test, pre-test, and post-test in both groups are displayed in table 1 .

Table 1. Descriptive statistics of all tests

\begin{tabular}{ccccc}
\hline Groups & Mean & Std. Deviation & Cases & rk \\
\hline $\begin{array}{c}\text { Control Group, proficiency } \\
\text { test }\end{array}$ & 25.4000 & 8.9002 & 30 & 0.8412 \\
\hline $\begin{array}{c}\text { Experimental Group, } \\
\text { proficiency test }\end{array}$ & 26.633 & 4.9722 & 30 & 0.7563 \\
& & & &
\end{tabular}

Since the proficiency test used in this study was a teacher-made localized test, it seemed necessary to investigate the reliability of the test. Table 2 . displays this information.

Table 2. The reliability of teacher-made placement test

\begin{tabular}{cccc}
\hline Groups & Mean & Std. Deviation & $\mathrm{N}$ \\
& & & \\
\hline Control Group, proficiency-test & 25.400 & 8.9002 & 45 \\
Control Group, pre-test & 6.3667 & 2.8826 & 30 \\
Control Group, post-test & 20.3000 & 5.3379 & 30 \\
& & & \\
\hline Experimental Group, proficiency-test & 26.6336 & & \\
Experimental Group, pre-test & 6.4333 & 4.9722 & 30 \\
Experimental Group, post-test & 24.2333 & 2.5688 & 30 \\
& & 6.6834 & \\
\hline
\end{tabular}

In order to find out whether the difference between the mean scores of the control group and the experimental group in the proficiency test was significant at the outset of the study, a t-test was conducted which is demonstrated in table 3 . The difference was not significant at .05 level of significance. 
Table 3. T-test between scores of proficiency test between two groups $(\mathrm{p}<* .05)$

\begin{tabular}{|c|c|c|c|c|}
\hline & \multicolumn{4}{|c|}{ t-test for Equality of Means } \\
\hline Scores of proficiency tests & $\mathrm{t}$ & $\mathrm{df}$ & Sig. (2-tailed) & Mean Difference \\
\hline Equal variances assumed & -0.663 & 58 & .510 & -1.233 \\
\hline
\end{tabular}

A t-test was also run to investigate the difference between the levels of vocabulary knowledge in the pre-test between the participants of both groups. The results displayed in table 4. reveal that the difference was not significant at .05 level of significance.

Table 4. T-test between scores of pre-test between two groups $(\mathrm{p}<* .05)$

In order to see the difference between the means scores of the post-test in two groups, another t-test was t-test for Equality of Means

\begin{tabular}{ccccc}
\hline Scores of pre-tests & $\mathrm{t}$ & $\mathrm{df}$ & Sig. (2-tailed) & Mean Difference \\
\hline $\begin{array}{c}\text { Equal variances } \\
\text { assumed }\end{array}$ & -0.095 & 58 & .925 & -6.6667 \\
\hline
\end{tabular}

conducted which showed a significant difference at 0.5 level of significance. The result of this t-test is displayed in table 5 .

t-test for Equality of Means

\begin{tabular}{ccccc}
\hline $\begin{array}{c}\text { Scores of post- } \\
\text { tests }\end{array}$ & $\mathrm{t}$ & $\mathrm{df}$ & Sig. (2-tailed) & Mean Difference \\
\hline $\begin{array}{c}\text { Equal variances } \\
\text { assumed }\end{array}$ & -2.519 & 58 & .015 & -3.9333
\end{tabular}

Table 5. test between scores of post-tests between two groups $(\mathrm{p}<* .05)$

\section{Disscusion}

The investigation of the results obtained from the study yielded the following conclusions. The result of t-test between the mean scores of the proficiency test (table 3.) produced no significant difference between the two groups. It means that the participants were probably homogenous having almost the same level of proficiency in L2 at the onset of the study. The analysis of the results of the t-test between the mean scores of the pre-test (table 4.) also revealed no significant difference between the previous knowledge of the participants of two groups. This finding also reveals that the participants in both groups possessed almost the same knowledge level in vocabulary before applying any treatment for the experimental group. The contents of table 5. reveal that the difference between the mean scores of the post-test in two groups wassignificant at the 0.5 level of significance, which is indicative of the effectiveness of the treatment in the experimental group and the acquisition of vocabulary incidentally. Considering this finding, it is concluded that the null hypotheses assumed in this study are rejected and the amount of acquisition in the two groups were different in favor of the experimental group. The analysis of the statistical one-way ANOVA also reveals that the difference between the means of the pre-test and post-test in two groups was significant. That is, the statistics supports that more vocabulary is acquired through incidental way than intentional way.

\section{Conclusion}

The results of this study revealed that the acquisition of vocabulary had occurred incidentally for the experimental group. EFL teachers may benefit from the results of this study, so that they can include new words in a real context and teach them through the context which more probably leads to incidental learning and ask learners to guess the meaning of items in context.This study may also have some implications for textbook writers. That is, in order to read and comprehend a text, a good knowledge of vocabulary is of the highest 
significance. Thus, incorporating at least some supplementary texts, particularly authentic short stories accompanied by attractive pictures to the English textbooks of high school by textbook writers seem $\mathrm{s}$ to be a practical and fruitful accomplishment, which may result in more exposure to vocabulary items in an authentic language and ultimately may lead to the incidental acquisition of vocabulary, as the findings of this study imply.

\section{References}

[1] V. F. Allen, Techniques in teaching vocabulary. Oxford University Press, 1983.

[2] A. Brian, Human Memory: Theory and Practice. Needham Heights, 2000.

[3] P. L. Carrel, Reading in a foreign language. London: Oxford University Press, 1998.

[4] R. Day, R. Richart, C. Omura, M, Hiramatsu. Incidental EFL vocabulary learning and reading. Reading in a foreign language, 7(2), 1991, 541-551.

[5] J. A. Fodor, Dynamic systems of language learning. Cambridge, MA: MIT Press, 1983.

[6] V. Greaney, M. Hegarty, Correlates of leisure-time reading. Journal of Research in Reading,10(2), 1987, 3-20.

[7] J. Hulstijn, Intentional and incidental second language vocabularyLearning.Cambridge, C.U.P, 2004.

[8] J. R. Jenkins, R. Dixon, Vocabulary Learning. Contemporary Educational Psychology, 8, 1983, 237-260.

[9] S. Krashen, The Power of Reading. Insights from the research. Englewood, Co, Libraries Unlimited, 1981-1985.

[10] S. Krashen, W. Pitts, We acquire vocabulary and spelling by reading: additional evidence for the input hypothesis. Modern Language Journal 73, 1989, 440-64.

[11] W. E. Nagy, R.C. Anderson, How many words are there in printed school English? Reading Research Quarterly, 19, 1984, 303330 .

[12] T. S. Paribakht, The relationship between reading comprehension and second language development in a comprehension-based ESL program. TESL Canada Journal, 11, 2001, 9-29.

[13] J. Read,Towards a deeper assessment of vocabulary knowledgePaper presented at the 8th Congress of the International Association of Applied Linguistics, Sydney, Australia, 16-21, and 1987.

[14] A.V. Rieder,Implicit and Explicit learning in incidental vocabulary acquisition. Retrieved July 25, 2004.

[15] A.V. Rieder, Implicit and Explicit learning in incidental vocabulary acquisition. Retrieved July 25, 2006.

[16] W. M. Rivers, Teaching foreign-language skills, Chicago, TheUniversity of Chicago Press, 1988, 1-30.

[17] S.A. Stahl, M. M. Fairbanks, The effects of vocabulary instruction: A model-based program for reading problems at any level. New York. Knopf, 1987.

[18] L. Taylor, Vocabulary in action. New York, Prentice Hall, 1990.

[19] DC. Washington, ERIC Clearing House on Languages and Linguistics.(ERIC Document Reproduction Service No, 301048.

[20] http;//www.univie.ac.at/anglistik/ang_new/online_papers/views/03_2/RIE_SGL E.PDF

[21] http;//www.univie.ac.at/anglistik/ang_new/online_papers/views/03_2/RIE_SGL E.PDF

[22] M. Retrieved February, from, http://www.ling.sophia.ac.jp/applied/youyaku/yoshioz.htm, 2005. 